Article

\title{
Resilience of Outdoor Spaces in an Era of Climate Change: The Problem of Developing Countries
}

\author{
Tali Hatuka * and Hadas Saaroni \\ Department of Geography and Human Environment, Tel Aviv University, POB, Tel Aviv, Israel; \\ E-Mail: saaroni@post.tau.ac.il
}

* Author to whom correspondence should be addressed; E-Mail: hatuka@ post.tau.ac.il;

Tel.: +972-3-6405162; Fax: +972-3-6406862.

Received: 9 October 2012; in revised form: 23 December 2012 / Accepted: 25 December 2012 / Published: 4 January 2013

\begin{abstract}
This paper recommends expanding research on the interrelations between climate change, cities, culture and the way climate change influences participants' thermal, emotional and perceptual well-being in public spaces as a key step in developing contextual design codes for outdoor public spaces. Proposing a general framework to address climate challenges in developing countries, the paper advocates focusing on the developing world, where outdoor spaces are extremely vulnerable and available studies are scarce.
\end{abstract}

Keywords: microclimate; outdoor public spaces; climate change; culture; design codes

\section{Introduction}

Urban planning has long been challenged to address sustainability and, recently, the impact of climate change on cities. The task of increasing cities' resilience is multi-faceted. One facet, unfortunately not a prominent one, is the fate of outdoor public spaces (e.g., streets, squares, and parks). Urban microclimates and outdoor thermal comfort are generally given little importance in urban design and planning processes, especially in developing countries [1-3]. To date, a growing body of research addresses the relationship between urban planning regulations and local microclimates [3,4]. This relationship presents a compelling field of study, given how modern society values outdoor public spaces as important assets, with a vast body of work addressing the significant social roles of these spaces as realms of contact and exchange among strangers. Socially, as a common territory that facilitates and regulates interpersonal relationships ("access") [5], outdoor spaces (and public spaces in 
particular) are where individuals display idealized selves adhering to (or challenging) cultural beliefs and behavioral patterns [6]. Contemporary criteria for defining the degree to which a space is public suggest that access, interest and agency are the key dimensions of that space's social organization, with space being offered as an asset in exchange. In this era of global climate change, however, we argue that the criteria for determining the degree to which a space is public must include environmental considerations if we are to support human comfort and the social role of public space.

Advocating design codes that consider human comfort in outdoor public spaces is relevant to cities worldwide, even more so for developing or under-developed countries [7]. Still, developing design codes is not a straightforward task. Although the threat of climate change is global, its implications are regional. Moreover, these changes' implications are subject to cultural, social and ethnic differences, rendering a global manual of "how to design public outdoor spaces" improbable. We suggest expanding the research on interrelations amongst climate change, cities, culture and the way climate change influences participants' thermal, emotional and perceptual well-being in public spaces as a key step in developing contextual design codes for outdoor public spaces. We also suggest focusing on the developing world, where outdoor spaces are extremely vulnerable and available studies are scarce. The remainder of this paper elaborates on our argument, beginning with a brief discussion of climate conditions and changes in developing countries, and it suggests a general framework to address climate challenges in developing countries. The aim of this study is to explain the pressing need for design codes for outdoor public spaces in developing countries in an era of global warming and climate extremes. A conceptual model for developing regional design codes is suggested to support human comfort and social life.

\section{What Is the Challenge? Quick Urbanization and Climate Change in Developing Countries}

The past several decades have ushered in a growing number of pessimistic reports on megacities in developing countries. With an increasing number of people occupying squatter settlements in the cities of the Global South [8], many states, NGOs and academic consultants have returned to using language that presents slums as dirty, diseased, criminal and depraved threats to society. Three well-known facts are often presented on slums in megacities: (a) approximately one billion people live in slum cities, mainly in the so-called Global South; (b) migration is increasing and is projected to double the slum population by 2030; and (c) current planning policies are often ineffective and slow to respond [9].

Why is this the case? In part, migration to cities is a dynamic phenomenon that is difficult to predict. Policy and urban development ensconced in rigid frameworks have difficulty tackling the large-scale, dynamic nature of the phenomenon. Moreover, the formal practices of urban development strategies tend to be abstract and often gloss over the heterogeneity and informal nature of megacities. In response, increasing research on the phenomena surrounding migration could be categorized as Marxist, pragmatic, and humanistic in perspective. Focusing on spatial inequalities and housing problems, the Marxist perspective [10] addresses slums as physical and spatial manifestations of urban poverty and intra-city inequalities arising from the contemporary political economy. Advocates see slum residents as a potential positive force of resistance that may be able to change the contemporary economic framework. The pragmatic perspective, as taken by states, the World Bank, NGOs and the $\mathrm{UN}$, is actively engaged with the question of what might be performed and how. Because slums are 
perceived as a threat to the order of the state, national approaches to slums, and to informal settlements in particular, include forced eviction, benign neglect and involuntary resettlement, as well as more positive policies such as self-help and in situ upgrading, enabling and rights-based policies [9].

Exploring both the negative and positive aspects of slums, the UN reports on intolerable conditions of urban housing, high concentrations of poverty, socio-economic deprivation and water-borne diseases; the UN also recognizes slums as entry points for immigrants, resulting in a vibrant mixing of different cultures. The latter suggests how the humanistic perspective, developed as early as the 1970s, focuses on social networks of the poor as a means of survival. Rather than decrying the social disorganization of the poor, scholars have addressed the ability of the poor to cope with extreme social and economic structural inequalities [11-13]. Some of these writings address the black market of unregistered businesses and home construction, amongst other examples, as a spontaneous, creative and popular response to the state's incapacity to spur production and distribution. Such informal systems are perceived as a way to resolve underdevelopment by reducing the state and expanding free enterprise [14].

This is not all. Beyond social challenges, megacities also face challenges from climate conditions and climate change. Most developing countries lie within regions characterized by extreme climate conditions and severe weather events, including the tropical regions, characterized by hot and humid conditions, and the subtropical regions, characterized by arid conditions. Climate significantly affects populations in tropical regions who are exposed to severe heat stress conditions from high temperatures and year-round humidity. Other difficulties include extreme rain events associated with floods as well as the destructive effects of tropical storms, hurricanes and typhoons [15]. The monsoon system, particularly the Asian and African monsoons, is typical of some tropical regions and affects more than half of humanity worldwide, causing intensive summer rains and floods as well as large inter-annual variability and severe droughts with vast environmental implications [16]. Populations in arid and semi-arid regions are also exposed to severe climate conditions, primarily to droughts causing water shortages and their associated environmental implications. Droughts appear at various timescales, from seasonal to yearly to decadal. Another difficulty is the human thermal discomfort resulting from high temperatures in the tropics and subtropics. Sultry conditions prevail in the tropics and along coastal areas in the subtropical regions as a combined effect of high temperatures and high humidity. Thus, developing countries in both tropical and subtropical regions are highly vulnerable to extreme weather conditions and to high inter-annual and intra-annual variability. These extreme conditions and variations directly impact everyday life, thermal comfort conditions, water availability (both upper and ground), agricultural potential and living and housing confidence. Stated differently, these climate conditions significantly influence the daily life of a population highly dependent on the natural environment. Relatively low living standards, undeveloped industrial bases and a low human development index further increase this dependency [17].

The vast, intensive process of urbanization enhances the difficulties of climate conditions, exposing populations to higher heat stress due to the urban heat island (UHI) effect. Although UHI intensities in tropical and subtropical cities are generally lower than those of temperate cities with comparable populations [18], intensive UHIs are found in cities located in low latitudes [19-22]. For example, a heat island intensity of up to $8.3{ }^{\circ} \mathrm{C}$ was detected in Delhi, India, with the highest magnitude during the afternoon and night hours [23]. The UHI shows a seasonal variation, with lower (higher) intensities during the wet (dry) season [18], indicating its larger effect in the dry season, which is characterized in 
these latitudes by the highest temperatures. Human thermal comfort is highly dependent on the mean radiant temperature (MRT) beyond the air temperature itself, being the highest in the low latitudes and especially in arid cities [24]. Thus, to increase human comfort within cities, it is recommended that strategies for reducing the MRT, and not only the air temperature, be considered when designing projects. Ali-Toudert et al. [25] indicate that UHI mitigation options improve the MRT more than options aimed at reducing the air temperature alone.

The discomfort conditions, implied by the climate conditions described, are further enhanced by climate change, including the low latitudes where most developing countries lie [26]. Beyond global and regional warming, tropical regions are becoming wetter, and the occurrence of severe rain events and floods is increasing. Conversely, the subtropical regions are drying, with an increase in droughts and water shortages [26]. Climate models are predicting a continuation of the warming trend and intensification of the hydrological cycle as a likely consequence of global warming [27]. Although there are uncertainties in predicted scenarios, most climate predictions, both global and regional, agree that a further increase in severe rain events in the tropics and drying in the subtropics is likely [26]. Seidel et al. [28] argue that this increase results from the poleward shift of the subtropical highs as part of the Hadley cell expansion, and they present evidence that the tropical belt has already expanded over the past few decades. A decrease in rainfall is predicted specifically for the Mediterranean Basin, based on all greenhouse emissions scenarios [29-34].

A most relevant local aspect of climate change is the intensification of the global warming trend in urban areas due to the urban heat island (UHI) effect. The rapid urbanization of cities in developing countries is associated with sharp intensifications of the UHI in these areas, enhancing the warming trend in those areas that suffer from severe heat stress conditions. For example, the UHI of the arid city of Beer Sheba, Israel, a city with a population of $\sim 200,000$ people, increased in the last 35 years by $2-3{ }^{\circ} \mathrm{C}$ beyond the regional warming, which is already greater than the global rate [35].

The Stern review on the economics of climate change [36] estimated that a $2{ }^{\circ} \mathrm{C}$ rise in global temperature costs approximately $1 \%$ of the world GDP. However, the World Bank, in its World Development Report [37], estimated that the cost to Africa and India will be closer to $4 \%$ and 5\% of the GDP, respectively, indicating the serious implications of climate change for developing countries. The effects of climate change on the populations of developing countries is far beyond the effects in developed countries, as shown, for example, by Ahmed et al. [38], who highlighted the higher poverty vulnerability to climate change of developing countries. The serious implications of climate change in these countries include lower agricultural yields, growing water stress, flooding of low-lying lands, and the spread of infectious diseases to warmer areas. In summary, these countries' rapid urbanization, their absence of climate adaptation planning, and the lack of green construction and sustainable development further increase the severe effects of climate change on the populations of fast-growing cities.

\section{Towards Establishing Design Codes for Outdoor Spaces in Developing Countries}

What can be done? How do we address the environmental challenges of developing countries? Where do we start? There is a growing body of research exploring the relationships between the built environment and climate. However, it seems that there are few studies on microclimate and thermal comfort in public spaces in developing countries, and even fewer on the impacts on the social 
dynamics of these countries and in an era of climate change. We suggest a generic conceptual framework for developing regional design codes for outdoor spaces, focusing on residents' daily lives (see Figure 1). This framework focuses on micro-scale planning and aims at enhancing interventions in outdoor spaces with a focus on thermal comfort conditions and liveability. The idea is to start with outdoor spaces rather than privates spaces (which require substantive funding), where the public can benefit as a whole. The goal is to develop regional design codes for outdoor spaces to enrich residents' everyday life while managing comfort conditions. This relatively modest approach, of thinking locally, could be implemented quickly with relatively basic resources.

How, then, do we address thermal comfort conditions while taking into account both users and the mitigation of climate change effects? In response to this question, we suggest what we call the Regional Codes for Outdoor Spaces (R-COS) Model (Figure 1). The power of this model is that it emphasizes local and regional conditions in the development of outdoor spaces, physically and culturally, and thus will contribute to more sustainable spaces. By sustainability, we refer to the role of the community in developing the codes (through interviews and public meetings) as well as maintaining and using the spaces developed. This is a crucial point in addressing developing countries, where the study of outdoor spaces is limited and, thus, there is a crucial need to better understanding tradition and daily habits.

This conceptual model includes three key steps towards developing Regional Codes for Outdoor Spaces: analytic, evaluative and regulative. The analytic step suggests that the study of outdoor spaces entails an investigation of the relationships between the physical and the cultural. First, the thermal comfort sensations that determine the body's energy balance should be estimated as an essential factor in open areas in regions known for uncomfortable climate conditions. Models estimating the energy balance of the human body typically include various meteorological parameters, including air temperature, air humidity, wind speed, short- and long wave radiation, surface albedo and solid angle proportion. Acknowledging the interrelations between climatic/physical conditions and cultural/social norms and traditions is crucial, as noted by Knez and Thorsson: "Different geographical/climatic zones can also be defined as different cultures [...] A member of a culture learns its rules and regulations, which she/he then shares with other members of the 'system'." [39,40]. The perceived world is a social and psychological construct and significantly influences place-related identity processes and an environmental attitude towards outdoor spaces [36]. Moreover, as has been noted, culture and traditions have crucial influences on clothing and on human comfort [3]. Furthermore, as has been shown by Knez and Thorsson, thermal, emotional and perceptual assessments of a physical place may intertwine with psychological and cultural processes rather than remain fixed by general thermal indices $[41,42]$.

The analytic step is followed by the evaluative step. This most crucial step focuses on estimating social groups' perception of comfort within a region or a city, defined as satisfaction with the thermal environment [43]. This step is performed using participant observations and interviews. In this step, one should carefully consider two parameters: (1) length of stay and (2) space typologies. One should divide the analytic results accordingly. For example, streets or urban corridors may have different functions and meanings than parks, squares or open courts near religious buildings. Furthermore, length of stay and exposure (to both physical conditions, such as direct sunlight and wind, and perceptions, such as aesthetics, the landscape, and users) can vary from one place to another, even 
though they may be adjacent. These differences may affect the thermal comfort as well as the perceptions of comfort.

Finally, based on comfort perception, the regulative step includes the development of design guidelines for outdoor spaces focusing on the following key related aspects: shading, vegetation, wind and ventilation, water use and materials. These aspects have a direct effect on thermal comfort and, thus, on its perception. Following the above, it is clear that shading, vegetation, ventilation, protection from strong winds and materials have a crucial impact on thermal comfort. Codes should incorporate percentages of shading, percentages of the area covered by water-intensive vegetation, the type of vegetation, design strategies for ventilation needed in hot and humid regions, protection from strong winds where needed, the color and type of coverage and other factors as well as a framework for implementation. As noted, this type of list should consider the conditions of the locale and should be regionally based. For example, the albedo of a particular surface, as well as the use of small artificial lakes, could have different impacts on different locales.

In addition to all the design codes offered, one must take into consideration the economic and social capacity of the society to maintain and enjoy these spaces. This point is crucial worldwide, but especially in the developing world, where funding is limited. Furthermore, one must take into consideration solutions that might enhance and support local development by using local materials and production. As a whole, the task of developing these codes is not obvious in either the developed or developing countries; it is a cultural and educational task that starts with policy makers, local inhabitants and designers. As has been shown by Hatuka and Saaroni [42], planners and residents are often committed to the image of the place and its aesthetics on the account of thermal comfort considerations. The analysis of a new urban park in Tel Aviv, Israel, adjacent to an ethnically mixed neighborhood, exposed the water-wasting landscape with minimal shading and the plantation of vast lawns.

Figure 1. A model for developing Regional-(Design) Codes for Outdoor Spaces (R-COS).

\begin{tabular}{|c|c|c|}
\hline & & REGIONAL-(DESIGN) CODES FOR OUTDOOR SPACES (R-COS) \\
\hline$\frac{\frac{n}{0}}{\frac{2}{\pi}}$ & 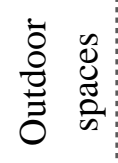 & $\begin{array}{ll}\text { Climate conditions } & \text { Culture and Traditions } \\
\text { Physical array } & \text { Social function and use }\end{array}$ \\
\hline 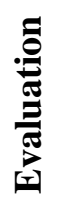 & 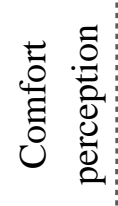 & $\begin{array}{l}\text { Time and Situation [i.e., length of exposure, type of clothing] } \\
\text { Space Typologies [i.e., squares, streets, parks] }\end{array}$ \\
\hline 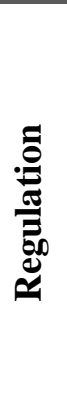 & $\begin{array}{l}\tilde{\theta} \\
\tilde{D} \\
0 \\
\tilde{0} \\
. \overline{0} \\
\tilde{0} \\
0\end{array}$ & $\begin{array}{l}\text { Defining (regionally based) sustainable design codes and taking into account } \\
\text { the role of the community in using and maintaining space to include: } \\
\text { - Measures for planting grass and vegetation } \\
\text { - Measures for shading percentage } \\
\text { - Measures for ventilation and strong wind protection } \\
\text { - Measures for allocation of water (including types) }\end{array}$ \\
\hline
\end{tabular}




\section{Conclusions}

Yahia [3] describes the (planned) outdoor spaces of Damascus: "The regulations for modern Damascus prescribe wide streets and pavements, large setbacks and relatively low building heights. This leads to a dispersed urban form where a large part of the buildings and streets are exposed to solar radiation. The existing planning regulations in Damascus have no requirements for shading for pedestrians, e.g., shading devices, arcades and projecting upper floors or shading trees." This quote exemplifies the need for climate adaptation planning and design codes to increase human thermal comfort in Damascus as well as in other cities in the world. Yahia's [3] urging to establish regulations to mitigate climate conditions is the right call. A city's outdoor spaces are its veins as well as the veins of a society's culture. In an era of intensifying UHIs on top of global warming, of extreme events such as heat waves and destructive storms, of drying and of increased water shortages in the subtropics, these types of codes will provide a feasible framework for supporting human comfort and sustainability, especially in developing countries. The underlying principle here is that design codes for outdoor spaces are not a luxury but a real step towards achieving socially just development.

Finally, the vulnerability of our daily life as well as our behavior in outdoor spaces should be observed in association with the gap between scientific knowledge (theory) and local landscape planning (practice) [43]. Although there is growing scientific research on the interrelationships between design and climate conditions from the individual unit to the city as a whole [44-49], most of these studies focus on (1) analyses of buildings from a climatologic perspective, mainly on the effect of architectural and structural design features (e.g., layout, window orientation, shading and ventilation) on human thermal comfort in indoor environments, and (2) Urban Heat Island (UHI) analyses that explore the effects of city design and the spatial array (i.e., density, building height, street geometry) on the intensity and spatial distribution of the UHI, which affects human thermal comfort in outdoor environments. However, while these studies have deeply explored relationships between the built environment and climates, it seems there are limited studies on microclimate and thermal comfort in public spaces in developing countries and their impacts on the social dynamics in these countries in an era of climate change. In other words, we know very little about the spaces between buildings, the very places that we all inhabit and use every day and in the highest intensity in developing countries.

\section{Conflict of Interest}

The authors declare no conflict of interest.

\section{References}

1. Eliasson, I.; Knez, I.; Westerberg, U.; Thorsson, S.; Lindberg, F. Climate and behavior in a Nordic city. Landscape Urban Plan. 2007, 80, 72-84.

2. Johansson, E. Influence of urban geometry on outdoor thermal comfort in a hot dry climate: a study in Fez, Morocco. Build. Environ. 2006, 41, 1326-1338.

3. Yahia, M.W. Microclimate and Thermal Comfort of Urban Spaces in Hot Dry Damascus, Influence of Urban Design and Planning Regulations. PhD thesis, Housing Development \& Management Lund University, Sweden, 2007. 
4. Erell, E.; Pearlmutter, D; Williamson, T. Urban Microclimate-Designing the Spaces between Buildings; Earthscan: London, Washington, DC, USA, 2011.

5. Sennet, R. The Fall of the Public Man; Cambridge university press: Cambridge, UK, 1976.

6. Goffman, E. The Presentation of Self in Everyday Life; Doubleday: New York, NY, USA, 1959.

7. Farlex Financial Dictionary. Available online: http://financial-dictionary.thefreedictionary.com/ less-developed+country, 2011. (accessed on 15 September 2012).

8. Odeh, L.E. A Comparative Analysis of Global North and Global South Economies. JSDA 2010, 3, $1-12$.

9. UN-Habitat. State of the World's Cities 2010/2011: Bridging the Urban Divide; UN-Habitat, 2008. Available online: http://www.unhabitat.org/content.asp?cid=8051\&catid=7\&typeid=46 (accessed on 15 September 2012).

10. Davis, M. Planet of Slums; Verso: New York, NY, USA, 2006.

11. Neuwirth, R. Shadow Cities: A Billion Squatters, A New Urban World; Routledge: New York, NY, USA, 2005.

12. Vélez-Ibañez, C.G. Rituals of Marginality: Politics, Process, and Culture Change in Central Urban Mexico, 1969-1974; University of California Press: Berkeley, CA, USA, 1983.

13. Selby, H.A.; Murphy, A.D. The Mexican Urban Household: Organizing for Self-Defense; University of Texas Press: Austin, TX, USA, 1990.

14. De Soto, H. The Other Path: The Invisible Revolution in the Third World; IB Taurus: London, UK, 1989.

15. McGregor, G.R.; Nieuwolt, S. Tropical Climatology: An Introduction to the Climates of the Low Latitudes; Wiley: New York, NY, USA, 1998; p. 339.

16. Cook, E.R.; Anchukaitis, K.J.; Buckley, B.M.; D’Arrigo, R.D.; Jacoby, G.C.; Wright, W.E. Asian monsoon failure and megadrought during the last millennium. Science 2010, 328, 486-489.

17. Human Development Report 2011. United Nations Development Programme (UNDP): New York, NY, USA, 2011; ISBN: 9780230363311.

18. Roth, M. Review of urban climate research in (sub)-tropical regions. Int. J. Climatol. 2007, 27, 1859-1873.

19. Sofer, M.; Potchter, O. The urban heat island of a city in an arid zone: The case of Eilat, Israel. Theor. Appl. Climatol. 2006, 85, 81-88.

20. Akinbode, O.M.; Eludoyin, A.O.; Fashae, O.A. Temperature and relative humidity distributions in a medium-size administrative town in southwest Nigeria. J. Environm. Management 2008, 87, 95-105.

21. Charabi, Y.; Bakhit, A. Assessment of the canopy urban heat island of a coastal arid tropical city: the case of Muscat, Oman. Atmos. Res. 2011, 101, 215-227.

22. Camilloni, I.; Barrucand, M. Temporal variability of the Buenos Aires, Argentina, urban heat island. Theor. Appl. Climatol. 2012, 107, 47-58.

23. Mohan, M.; Kikegawa, Y.; Gurjar, B.; Bhati, S.; Kandya, A.; Ogawa, K. Urban heat island assessment for a tropical urban air shed in India. Atmos. Clim. Sci. 2012, 2, 127-138.

24. Emmanuel, R.; Fernando, H.J.S. Urban heat islands in humid and arid climates: role of urban form and thermal properties in Colombo, Sri Lanka and Phoenix, USA. Clim. Res. 2007, 34, 241-251. 
25. Ali-Toudert, F.; Djenane, M.; Bensalem, R.; Mayer, H. Outdoor thermal comfort in the old desert city of Beni-Isguen, Algeria. Clim. Res. 2005, 28, 243-256.

26. IPCC 2007: Climate Change 2007: The Physical Science Basis. Contribution of Working Group I to the Fourth Assessment Report of the Intergovernmental Panel on Climate Change; Solomon, S., Qin, D., Manning, M., Chen, Z., Marquis, M., Averyt, K.B., Tignor, M., Miller, H.L., Eds.; Cambridge University Press: Cambridge, UK, 2007.

27. Williams, P.D.; Guilyardi, E.; Sutton, R.; Gregory, J.; Madec, G. A new feedback on climate change from the hydrological cycle. Geophys. Rese. Lett. 2007, 34, L08706.

28. Seidel, D.J.; Fu, Q.; Randel, W.J.; Reichler, T.J. Widening of the tropical belt in a changing climate. Nat. GeoSci. 2008, 1, 21-24.

29. Lionello, P.; Giorgi, F. Winter precipitation and cyclones in the Mediterranean region: future climate scenarios in a regional simulation. Adv. GeoSci. 2007, 12, 153-158.

30. Alpert, P.; Krichak, S.O.; Shafir, H.; Haim, D.; Osetinsky, I. Climatic trends to extremes employing regional modeling and statistical interpretation over the E. Mediterranean. Glob. Planet. Change 2008, 63, 163-170.

31. Kitoh, A.; Yatagai, A.; Alpert, P. First super-high-resolution model projection that the ancient "Fertile Crescent" will disappear in this century. Hydrolo. Res. Lett. 2008, 2, 1-4.

32. Jin, F.; Kitoh, A.; Alpert, P. Water cycle changes over the Mediterranean: a comparison study of a super-high-resolution global model with CMIP3. Phil. Trans. Roy. Soc. A 2010, 368, 1-13.

33. Raible, C.C.; Ziv, B.; Saaroni, H.; Wild, M. Winter synoptic-scale variability over the Mediterranean Basin under future climate conditions as simulated by the ECHAM5. Clim. Dyn. 2010, 35, 473-488.

34. Krichak, S.O.; Breitgand, J.S.; Samuels, R.; Alpert, P. A double-resolution transient RCM climate change simulation experiment for near-coastal eastern zone of the Eastern Mediterranean region. Theor. Appl. Climatol. 2011, 103, 167-195.

35. Saaroni, H.; Ziv, B. Isolating the urban heat island contribution in a complex terrain and its application for an arid city. J. Appl. Meteor. Climatol. 2010, 49, 2159-2166.

36. Stern, N. The Stern Review on the Economics of Climate Change; HM Treasury: Cambridge, UK, 2006; ISBN number: 0-521-70080-9.

37. World Bank. World development report 2010: Development and climate change. Available online: http://wdronline.worldbank.org/worldbank/a/c.html/world_development_report_2010/abstract/W B.978-0-8213-7987-5.abstract (accessed on 15 September 2012).

38. Ahmed, S.A.; Diffenbaugh, N.S.; Hertel, T.W. Climate volatility deepens poverty vulnerability in developing countries. Environ. Res. Lett. 2009, 4, 034004.

39. Knez, I.; Thorsson, S. Thermal, emotional and perceptual evaluations of a park: Cross-cultural and environmental attitude comparisons. Build. Environ. 2008, 43, 1483-1490.

40. Knez, I.; Thorsson, S. Influences of culture and environmental attitude on thermal, emotional and perceptual evaluations of a public square. Int. J. Biometeorol. 2006, 50, 258-268.

41. Humphreys, M.; Nicol, F.; Roaf, S.; Sykes, O.; Standards for Thermal Comfort: Indoor air Temperature Standards for the 21st Century; E \& FN Spon: London, UK, 1995. 
42. Hatuka, T.; Saaroni, H. The Need for Advocating Design Codes in an Era of Climate Change: A Case Study of a Mediterranean Urban Park. Landscape Review 2012, doi:10.1080/01426 397.2012.720249.

43. Eliasson, I. The use of climate knowledge in urban planning. Landscape Urban Plan. 2000, 48, 31-44.

44. Aronin, J.E. Climate and Architecture; Reinhold: New York, NY, USA, 1953.

45. Evans, J.M.; Schiller, S. Application of microclimate studies in town planning: a new capital city, an existing urban district and urban river front development. Atmos. Environ. 1996, 30, 361-364.

46. Farr, D. Sustainable Urbanism: Urban Design with Nature; Wiley: Hoboken, NJ, USA, 2008.

47. Register, R. Ecocities: Rebuilding Cities in Balance With Nature; New Society Publishers: Gabriola, BC, USA, 2006.

48. Wheeler, S. Planning for Sustainability: Creating Livable, Equitable, and Ecological Communities; Routledge: New York, NY, USA, 2004.

49. Wheeler, M.S.; Beatley, T. The Sustainable Urban Development Reader; Routledge: London, New York, 2004.

(C) 2013 by the authors; licensee MDPI, Basel, Switzerland. This article is an open access article distributed under the terms and conditions of the Creative Commons Attribution license (http://creativecommons.org/licenses/by/3.0/). 